\title{
The popular culture of computer scientists... : addendum - the future past.
}

\author{
Camille Akmut
}

July 30, 2019

\begin{abstract}
The remaining X-Files : including one episode about an NSA whistleblower and one about a modern Oppenheimer or Midas.
\end{abstract}




\section{Foreword}

One of the great pleasures - few in an otherwise difficult task - derived from looking into the past is discovering hidden within it mirrors of our own days; but, painful too because simultaneously reflection of ourselves.

In this last addition to our study on representations of computer scientists we complete our review of The X-Files interrupted mid-way through only to create space for newer, less established media; and to give them the attention they deserve.

One of the last episodes entitled "Trust No 1" in particular strikes as prescient and of particular relevance to our contemporary times : there an NSA whistleblower tried to expose "crimes against innocent people". (Broadcast January 2002.)

In another, a US Census Bureau employee does the same: "Fight the Future".

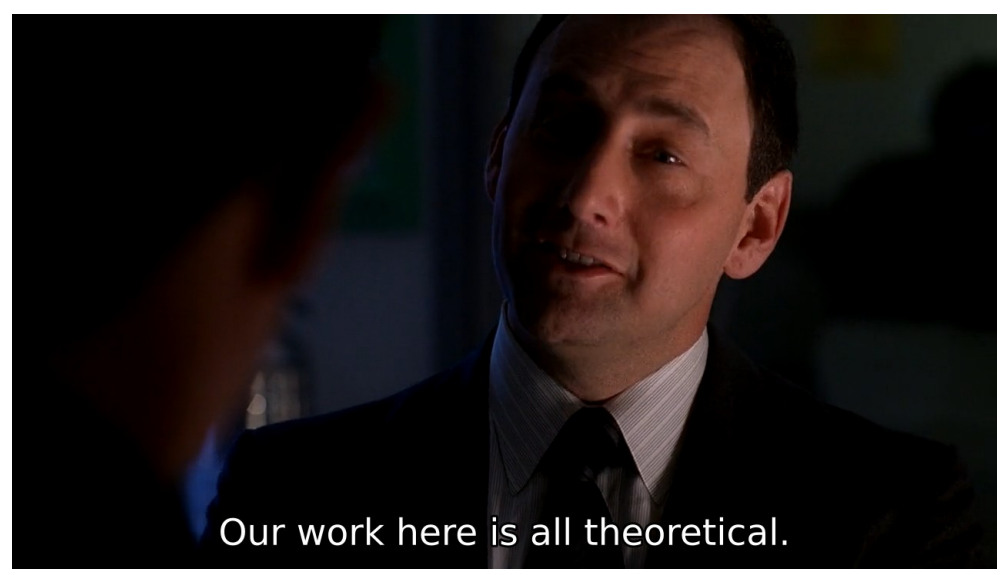

Figure 1: "Theoretical" scientist (The X-Files).

In another yet, a scientist makes assurances : "Our work here is all theoretical.", he says - parrot to many current-day computer scientists.

He promises "indestructible things"; like his peers he lacks a proper education, and has not heard of the tale of Midas, who wanted to make everything gold, only to learn through dire experiences the consequences of his ideals, acts. "Smart metals" there, "smart homes" here.

The latest Turing Award was given to LeCun and Hinton - we have just learned. If the jury of this prize had agreed to pick the worst candidates possible, they would have come up with these same names.

What an upside-down culture!

Its members not only clueless of who they are, but more importantly who they could be. Or, maybe they "just didn't care" ... 


\section{The $X$-Files (1993-2002)}

\subsection{Selected episodes}

\begin{tabular}{|l|l|}
\hline S08E09 ("Salvage") & "purely theoretical" scientists with not-so theoretical results. \\
\hline S08E16 ("Three Words") & $\begin{array}{l}\text { US Census Bureau whistleblower. (Lone gunmen re-unite with } \\
\text { Mulder post-disappearance.) }\end{array}$ \\
\hline S09E06 ("Trust No 1") & NSA whistleblower. \\
\hline
\end{tabular}

\subsection{Selected excerpts}

S08E09

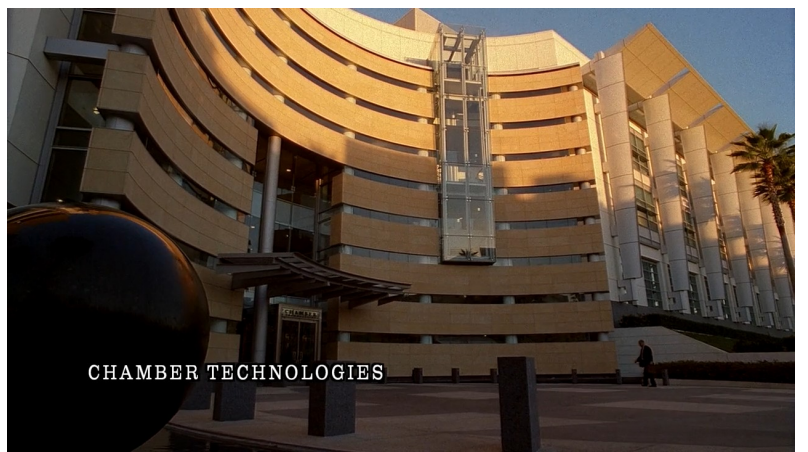

(a) The more conservative, respectable architecture preferred by some technology companies.

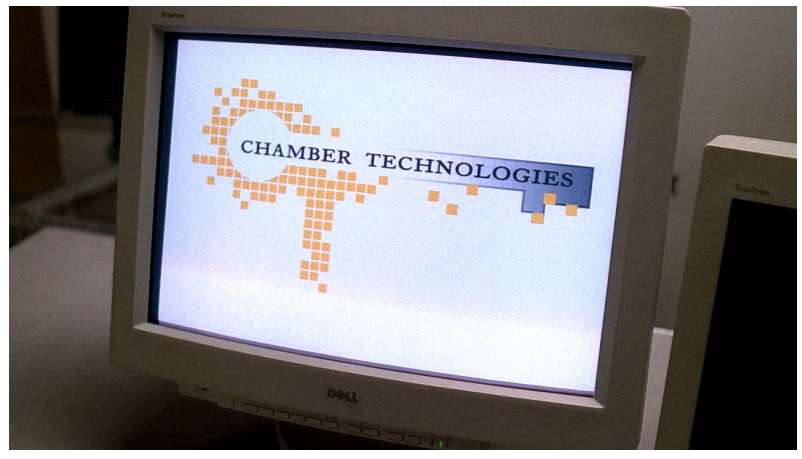

(b) Company logo.

Figure 2: Chamber Technologies in The X-Files.
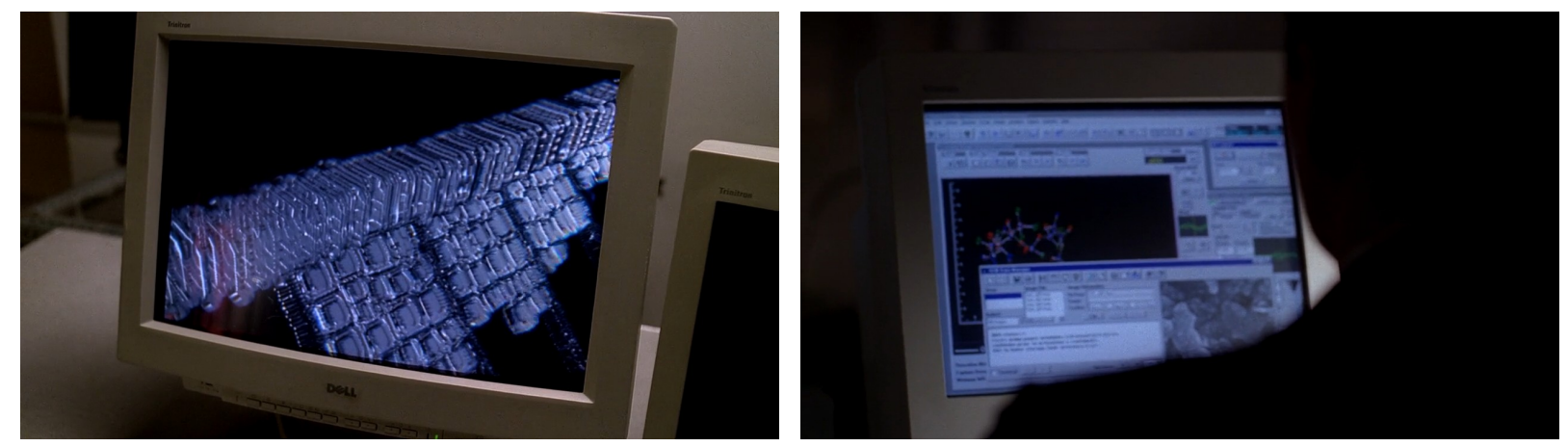

Figure 3: "smart" metals (l.) / computer program (r.). 
Dr Puvogel - They're called "smart metals".

The idea is to one day build things that are indestructible.

Cars, equipment... Built of alloys with molecular memory.

$(\ldots)$

Doggett - An employee number on the document was assigned to a Dr David Clifton. Dr Puvogel - Uh, Dr Clifton's no longer here.

Doggett - What happened to him?

Dr Puvogel - He left the company.

(...)

Dr Puvogel - I don't deal with materials. Nor did Dr Clifton for that matter.

Our work here is ALL theoretical.

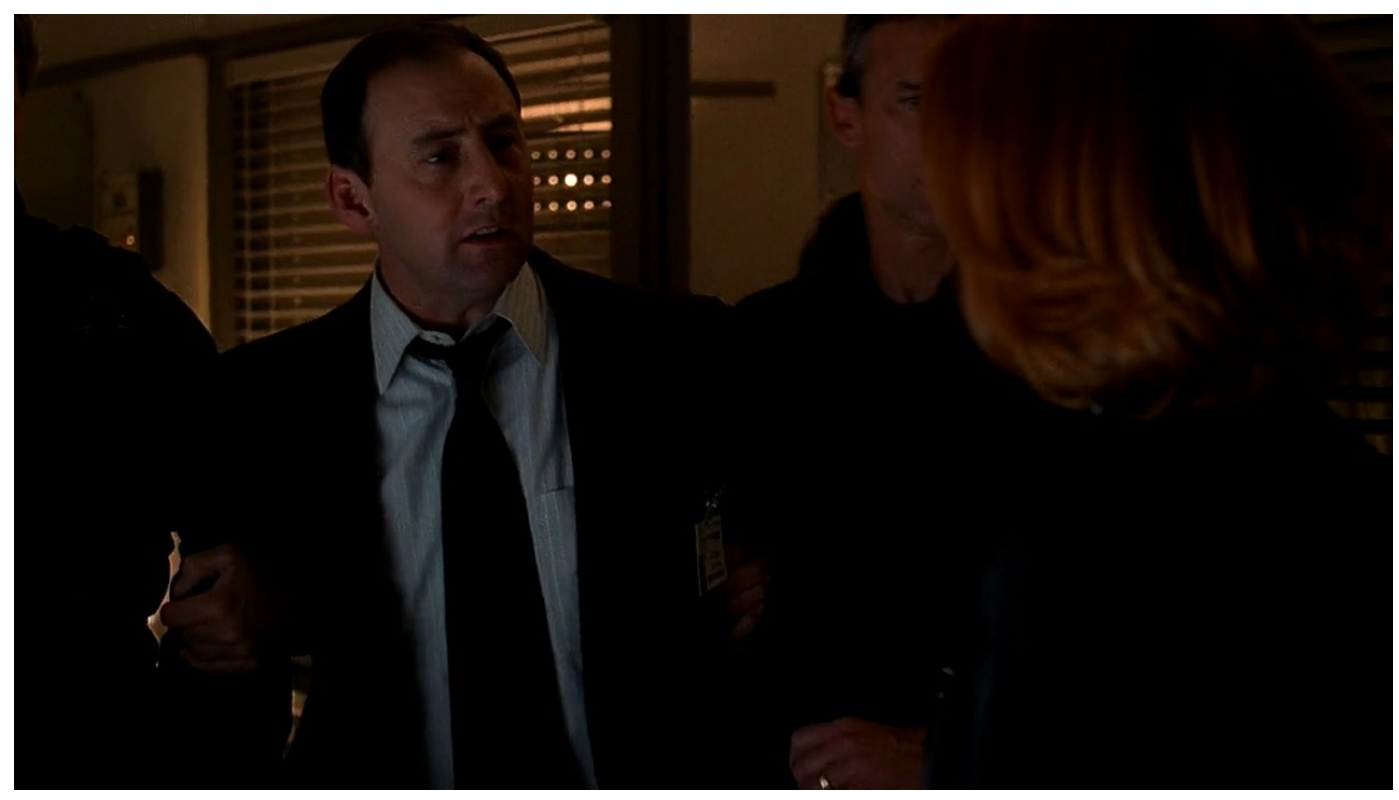

Figure 4: (computer) scientist under arrest.

Dr Puvogel - What's going on here?

It's not enough that my life's been threatened.

I'm being treated like a criminal.

Scully - And, not without cause.

\section{S08E16}

Scully - The Gunmen were able to decrypt the data that you found on Howard Salt's hard drive. It was a series of file directories that were downloaded the day that he died.

Mulder - Downloaded from where?

Langly - The FSC: the Federal Statistics Center.

Byers - A government information bank used by the US Census Bureau where your Mr. Salt worked. 

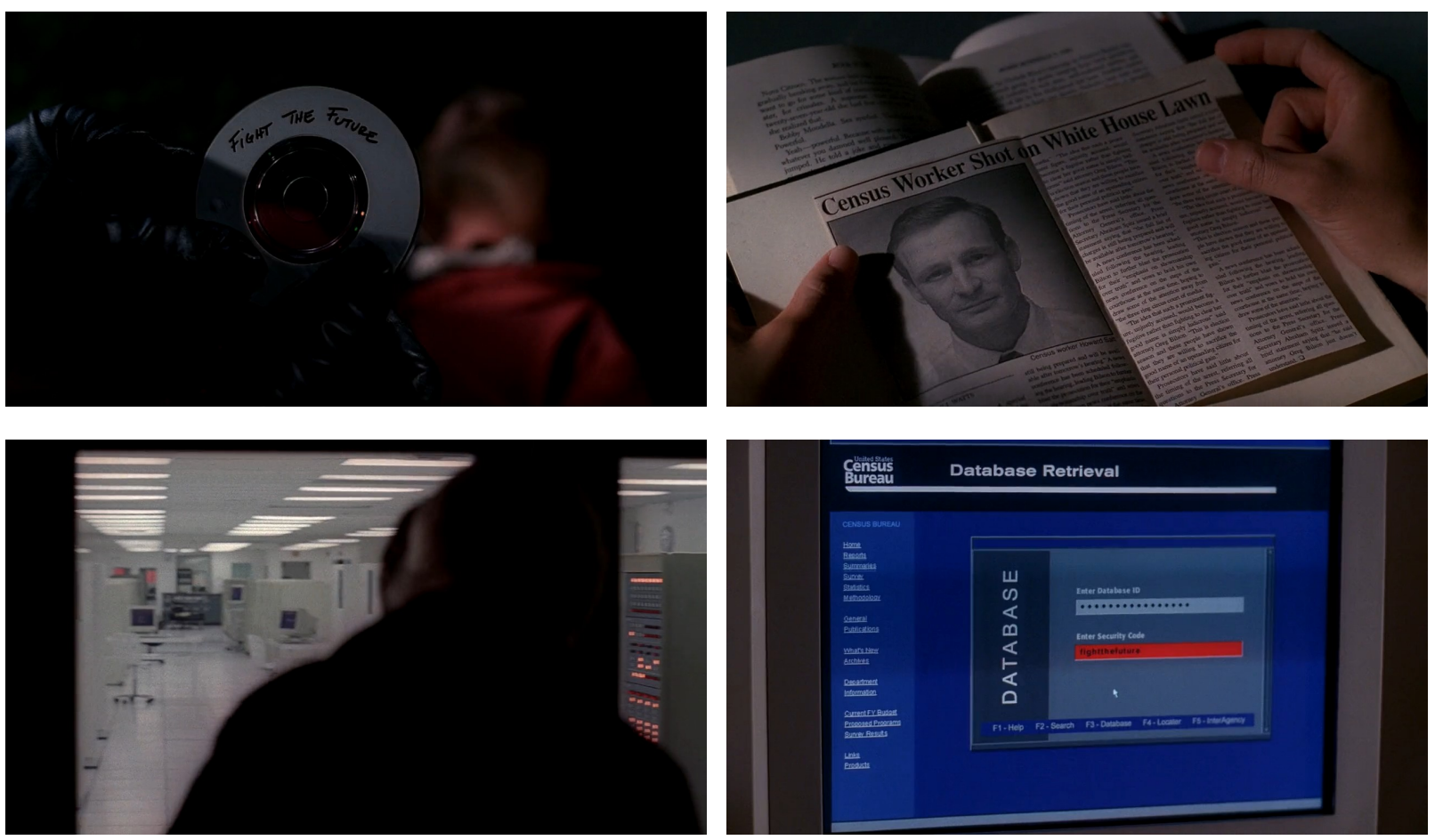

Figure 5: Howard Salt (above) / Federal Statistics Center (below).

Langly - And, even if you have a passcode, you still have to break into the FSC just to use it. (...)

Mulder - Well, just remember boys : this is America.

Just because you get more votes, doesn't mean you win.

\section{S09E06}

Reyes - He says he has highly classified military files.

$(\ldots)$

- I work for the National Security Agency.

The name on my driver's license is false.

If you were to call the police, I would be detained only long enough for another NSA agent to authorize my release.

I don't exist as a citizen, nor does anyone I work with.

$(\ldots)$

Doggett - How do you know anything about her (...)?

- I know virtually everything about you.

And you.

And you. 
$(\ldots)$

Reyes - So you've been looking in this apartment with what? Cameras?

- Various forms of technology.

$(\ldots)$

- My scope is limited.

I only look at what they tell me to. (...) But I have a supervisor (...)

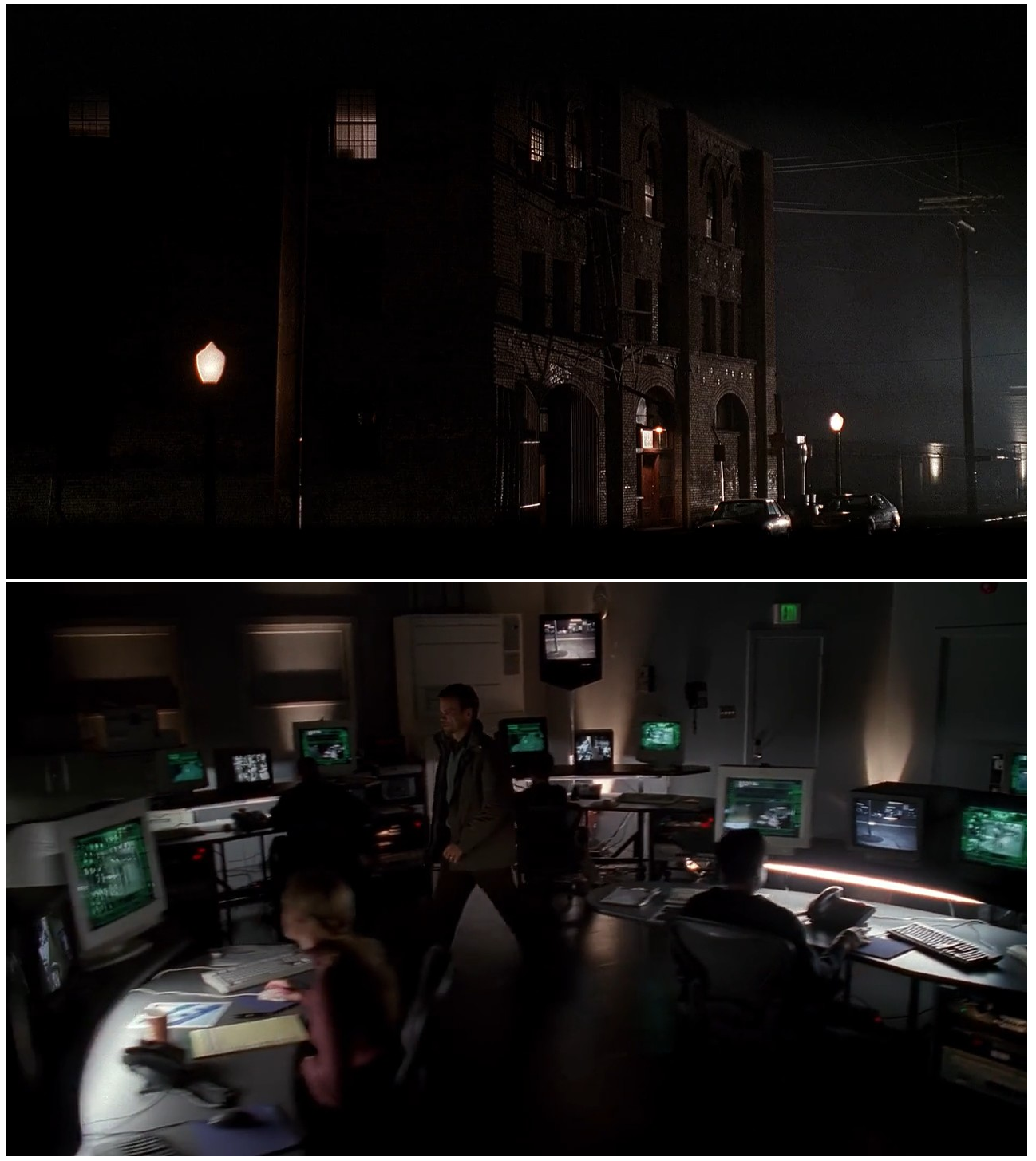

Figure 6: (unmarked) NSA building - as depicted in The X-Files. 
$(\ldots)$

Doggett - I ran a trace. (...) [but] got a node.

Sector of six city blocks.

Area's vacant except for this building.
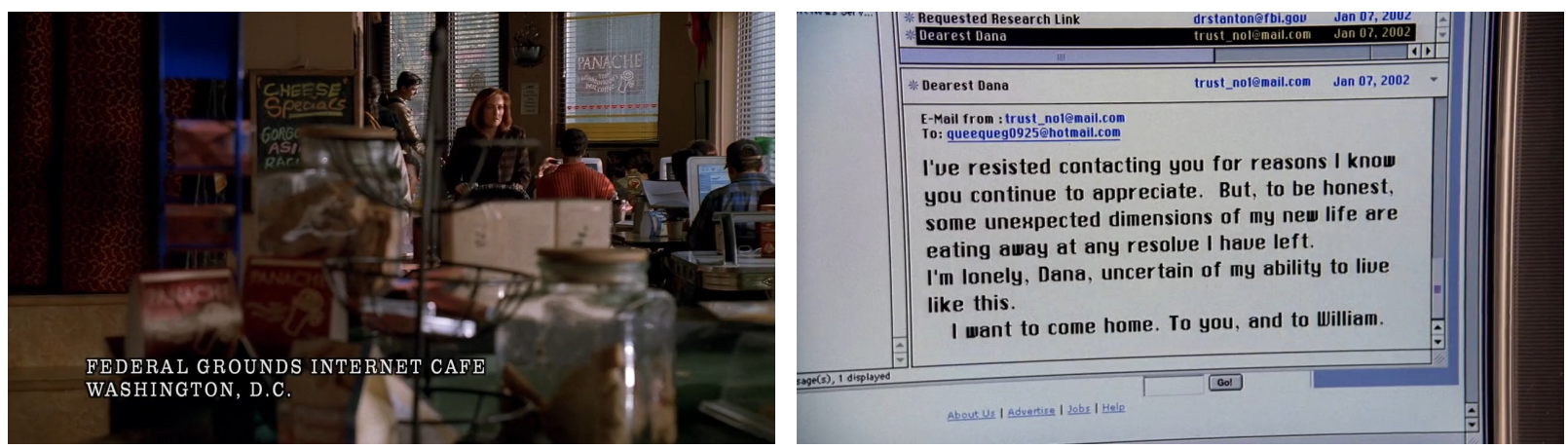

Figure 7: Internet cafe where the NSA agent(s) first appeared.
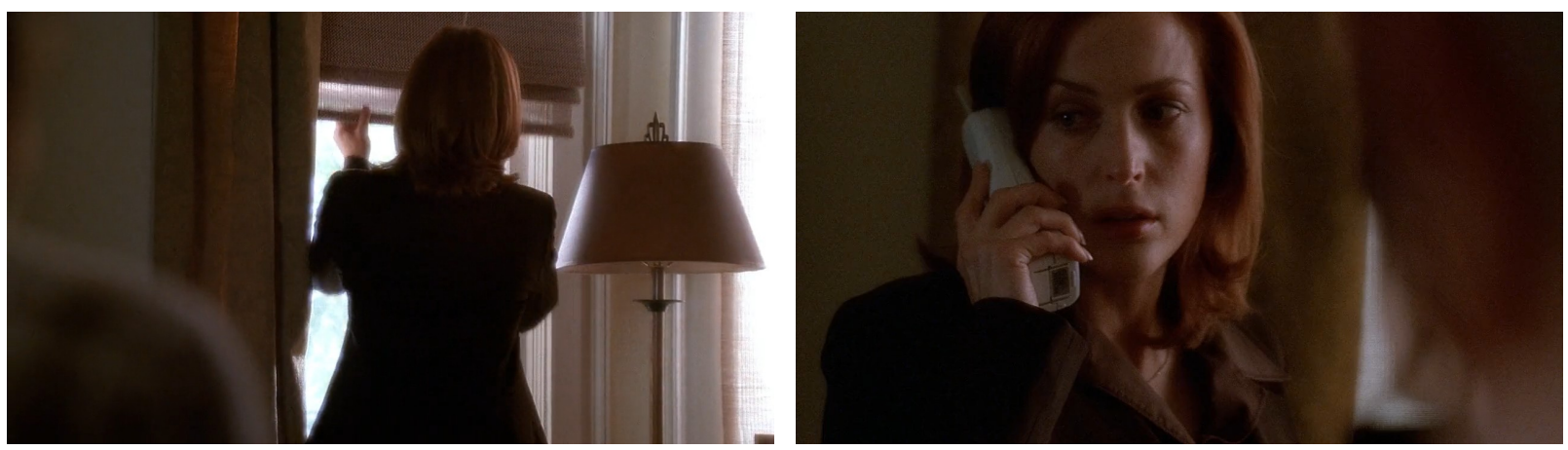

Figure 8: Scully closing shades (l.) / on the phone with NSA supervisor (r.).

NSA agent - They're watching.

Doggett - They're watching?

[Scully covers the windows.]

$(\ldots)$

[*disguised voice]

NSA supervisor* - As my associate indiscreetly told you, we don't have names.

Scully - You've been listening to us?

NSA supervisor - It's all I could do after you closed the shades. Agent Scully.

Scully - You ever heard of the Constitution? 
$(\ldots)$

Scully - What have they done?

NSA supervisor - It's what they're prepared to do next.

$(\ldots)$

Scully - Tell me. I don't know how to reach him.

NSA supervisor - But, you reached him yesterday.

You sent him an e-mail. Would you like me to read it to you?

Scully - Why should I trust you?

$(\ldots)$

Scully - We're in the middle of nowhere!

NSA supervisor - There is no "middle of nowhere" any more.

$(\ldots)$

NSA supervisor - Your watch. Give it to me.

Scully - This is ridiculous. This has gone far enough.

[She consents, he checks the watch, then gives it back to her.]

$(\ldots)$

NSA supervisor - Your size? I know your blood type, your resting heart rate, your childhood (...)

I know the name of your college boyfriend, your true hair color, your ATM PIN number.

Favorite charities, pet peeves.

I know you spend too much time alone. And, I know that on one lonely night ...

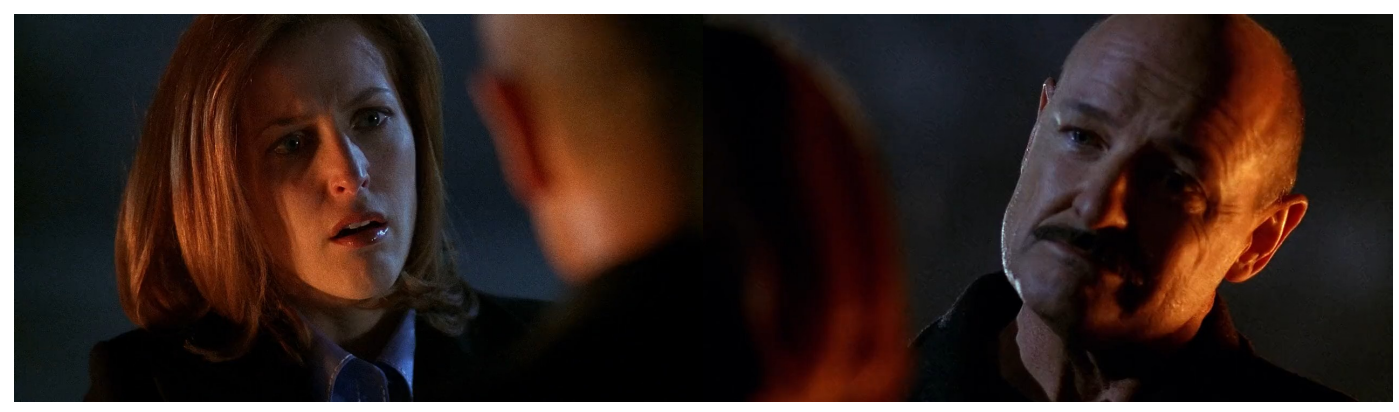

Figure 9: Face-to-face meeting with NSA supervisor (The X-Files).

$(\ldots)$

NSA supervisor - I was as surprised as you are.

Scully - Who authorizes you? I mean, what gives you the right? Who are you?!

NSA supervisor - I'm the future 

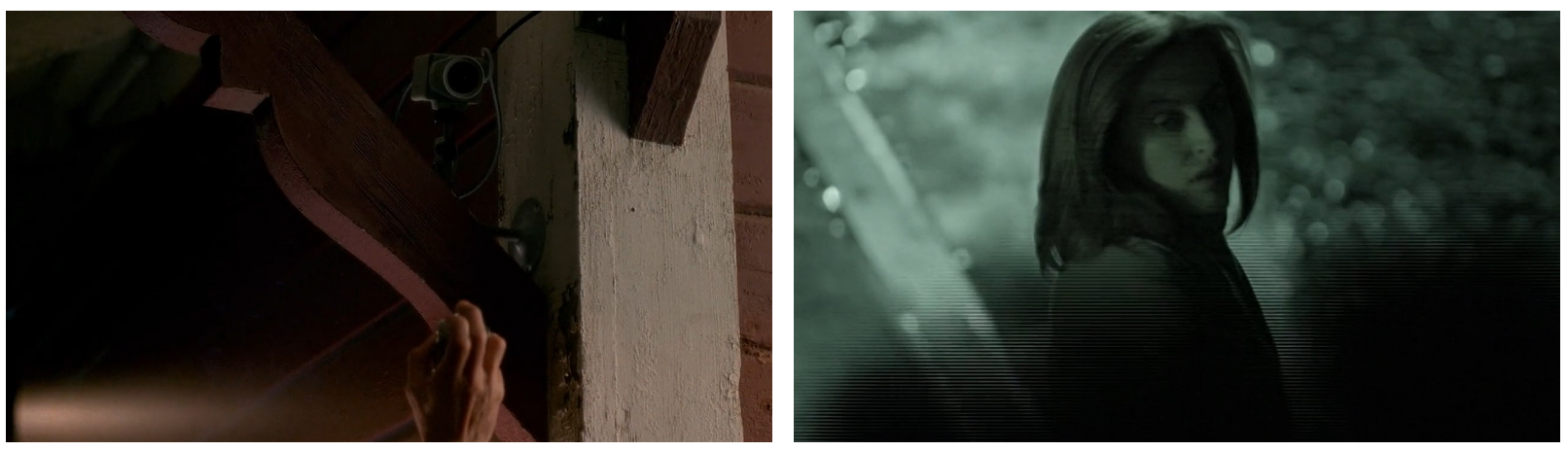

Figure 10: NSA agent spray painting over camera (The X-Files).

\section{$1.3 \quad$ Notes}

- In episode S08E16, as far as we know multiple invalid IP addresses (e.g. 320.xxx and 257.xxx) were displayed.

Character Langly commented "I can't get it uploaded, let alone start transmission" (naively), while Mulder had just been shown successfully downloading from/to them; but both should be impossible in our current system, at least (range $0-255$ ).
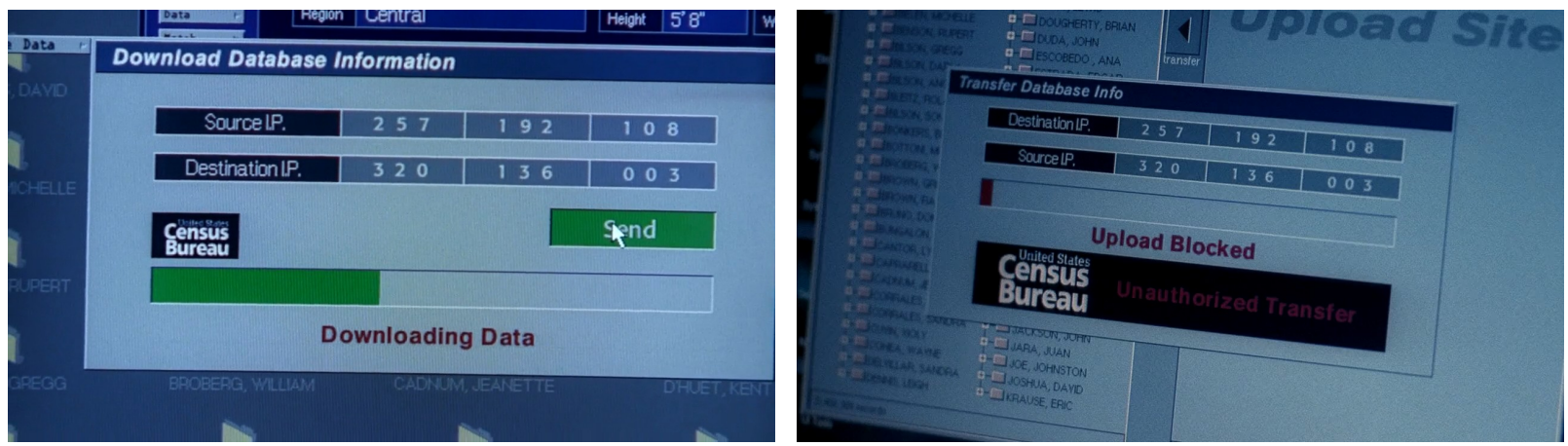

Figure 11: Mulder (left) / Langly (right) in S08E16.

— In episode S09E06, we characterized the (NSA) building shown in figure 6 as "unmarked" :

For real such buildings, see the The Intercept's exemplary article "The NSA's Hidden Spy Hubs in Eight U.S. Cities".

— In the same episode, Mulder uses the e-mail address : trust_no1@mail.com.

The whistleblower insists on communicating with Mulder alone / only

(by then quite well-known, if not public figure).

No visible form of encryption is used between Scully and Mulder. 